\title{
No More Special Relationship in Kensington
}

The Imperial College of Science and Technology, part of the University of London, is not cast down by the wave of despondency which is overtaking the universities. Realizing that public funds are not likely to be forthcoming, Imperial College this week opened an appeal for $£ 2$ million. This implies a recognition that the special position which the college has held since 1953, when it was singled out for rapid expansion, is to all intents and purposes at an end. In the decade from 1953 the number of students at Imperial College was almost doubled to roughly 3,000 . A second stage of expansion began in 1965, and roughly three-quarters of the work is now complete. Only a building for mathematics, meteorology and computing and part of the chemistry building are still at the planning stage. The number of students at Imperial College is now 3,795, of which just over 1,500 are postgraduates.

The site of Imperial College - just behind the Albert Hall in fashionable west London-is the root cause of the problems which the college is now facing. For one thing, students and junior staff cannot afford to live near the laboratories unless they are lucky enough to have a place in one of the halls of residence in nearby Prince's Gardens. Another problem is that the primarily residential district of Kensington in which Imperial College is situated does not regard the college as its local university. And, unlike many provincial universities, Imperial College does not in any case have industry nearby on which to fall back for support.

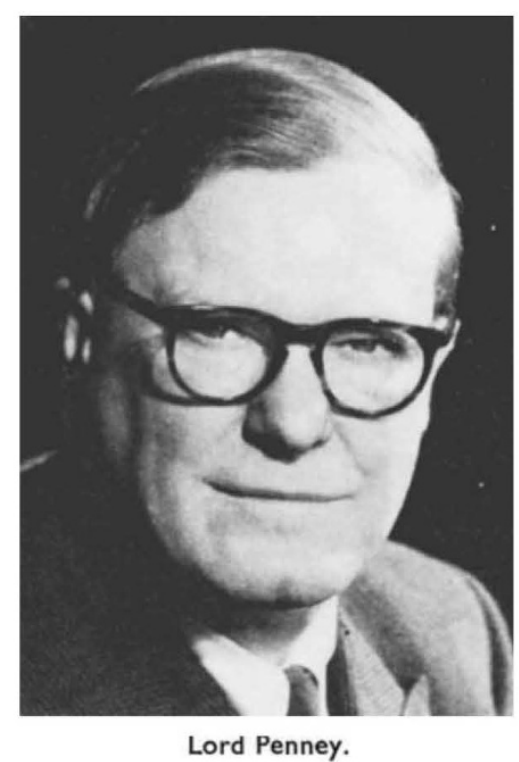

Apart from the problem of accommodation, which is to swallow $f 1 \cdot 1$ million of the appeal, the college is asking for $£ 700,000$ for research and teaching purposes. On top of this, $£ 200,000$ is needed for development of the Silwood Park field station, near Ascot, adding up to the target figure of $£ 2$ million.

The shortage of living accommodation is the problem which is particularly worrying Lord Penney, the Rector of Imperial College. The enthusiasm of the young students and staff has impressed Lord Penney since he went to Imperial College a year ago, and he is eager to provide the best facilities for them. A survey last year found almost by accident that more than 500 students seem to be in the habit of working in the college during weekend afternoons, for example. Lord Penney believes that many students are put off from using the college outside normal hours because of long journeys to their lodgings. Eager that his science and technology students are not typed as narrow-minded, he also believes that more student residences would encourage the cultural life of the college. College accommodation should also prove cheaper-two years ago 71 per cent of the students who did not live at home or in the college paid two-thirds of their grant on food and lodgings, roughly $£ 610 s$ a week. This expenditure is likely to be more now. At least one year in college accommodation for every student is the aim. Roughly 700 more places in halls of residence and student houses are needed to reach this target by 1973.

The $£ 700,000$ which is requested for research and teaching purposes is for a variety of uses. Lord Penney lists the support of research projects which have not yet reached the stage when the research councils or industry can be asked to contribute, the provision of eaching equipment and the financing of an environment of scientific equipment in which research is likely to prosper. Silwood Park, the field station of Imperial College, is to be the third beneficiary. It is here that the college carries out biological work, notably on pesticides and parasitology.

The building work which has been going on at Imperial College's 16 acre site since 1954 is therefore not at an end. Apart from the building of new residences and the conversion of existing houses into student accommodation, which will start if the appeal is successful, there are plans for a school of architecture to be built in Queen's Gate (Nature, 220, 635; 1968).

These plans are based on an agreement that the school of the Architectural Association will become part of Imperial College after the school moves, on the expiry of its lease, from its present buildings in Bedford Square. At present the school is independent, but if the merger takes place it will of course become part of the university system. The move is dependent on the Architectural Association raising $£ 500,000$ for the new building in Kensington, however. Naturally enough, Imperial College feels this sum should not come out of the budget earmarked for science and technology. Lord Penney says Imperial College has no further plans for broadening the scope of the subjects it teaches, beyond the science and engineering which it offers at present. The suggestion in the Todd report that the college should have a medical faculty seems to have fallen by the wayside for the time being at least, but Lord Penney does not seem adverse to the notion of post-medical research at Imperial College. 